Article

\title{
Fluorescence Assay for the Determination of D-Panthenol Based on Novel Ring-Fused 2-Pyridone Derivative
}

\author{
Wiktor Kasprzyk $^{1, *}{ }^{\text {, Tomasz Świergosz }}{ }^{2}$ [D and Filip Koper $^{1}$ \\ 1 Department of Biotechnology and Physical Chemistry, Faculty of Chemical Engineering and Technology, \\ Cracow University of Technology, Warszawska 24, 31-155 Kraków, Poland; filipkoper1@gmail.com \\ 2 Department of Analytical Chemistry, Faculty of Chemical Engineering and Technology, \\ Cracow University of Technology, Warszawska 24, 31-155 Kraków, Poland; tomasz.swiergosz@pk.edu.pl \\ * Correspondence: wiktor.kasprzyk@pk.edu.pl
}

Received: 25 October 2020; Accepted: 6 November 2020; Published: 9 November 2020

\begin{abstract}
Herein, a novel fluorescent method for the determination of D-panthenol (DP) level in solutions with no separate hydrolysis step has been revealed based on the utilization of citric acid (CA) as a derivatizing agent. Consequently, the essential parameters of the derivatization process were established, resulting in the development of sensitive, repeatable, and accurate determination of panthenol. The method was approved, and its usefulness in characterizing the concentration of DP in pharmaceutical formulations and selectivity in the determination of DP were validated. The chemical structure of the new fluorophore formulating in the reaction in DP with CA, i.e., 6-oxo-3,4-dihydro-2H,6H-pyrido[2,1-b][1,3] oxazine-8-carboxylic acid (ODPC), was elucidated using detailed NMR experiments: one-dimensional $\left({ }^{1} \mathrm{H},{ }^{13} \mathrm{C}\right)$ as well as two-dimensional NMR spectra $\left({ }^{1} \mathrm{H}_{-}{ }^{1} \mathrm{H}\right.$ COSY, ${ }^{1} \mathrm{H}_{-}{ }^{13} \mathrm{C}$ HSQC,${ }^{1} \mathrm{H}_{-}{ }^{13} \mathrm{C}$ HMBC,,${ }^{1} \mathrm{H}_{-}{ }^{15} \mathrm{~N}$ HSQC,${ }^{1} \mathrm{H}_{-}-{ }^{15} \mathrm{~N}$ HMBC$)$.
\end{abstract}

Keywords: D-panthenol; citric acid; fluorescence; derivatization; ring-fused 2-pyridones

\section{Introduction}

D-panthenol (DP) (IUPAC name: (2R)-2,4-dihydroxy-N-(3-hydroxypropyl)-3,3-dimethylbutanamide) is an alcohol analog of vitamin B5 (pantothenic acid). Due to its enhanced stability, panthenol is mainly used as an ingredient in many pharmaceutical and cosmetical formulations. It has moderate irritating properties and is non-allergenic and not mutagenic [1-3]. After application of D-panthenol to the skin, it is readily absorbed and transformed into pantothenic acid, promoting new cell growth, binding water, and acting as a moisturizer. Vitamin B5 is an important component of Coenzyme A, known for its vital role in the metabolism of carbohydrates, fats, and nitrogen compounds. Lack of pantothenic acid causes many types of deficiency diseases, skin irritation, dermatitis, hair depigmentation, and growth inhibition [4]. DP is applied externally to increase the epithelialization of burns and scratch wounds and ulcers [5-7]. It is associated with the fact that pantothenic acid is essential for maintaining the proliferation and differentiation of keratinocytes as it regulates the epidermal barrier function by proliferation and differentiation of keratinocytes directly or indirectly through the synthesis of KGF (Keratinocyte Growth Factor) and type IV collagen [6].

DP as an aliphatic alcohol free of conjugated bonds and chromophores does not exhibit absorption in either the near-ultraviolet $(300-400 \mathrm{~nm})$ or the visible part of the electromagnetic spectrum. Nevertheless, direct spectrometric methods for the determination of DP after chromatographic separation have been reported [8-11]; however, these suffer from a lower sensitivity [8]. Other direct DP assays characterized in the literature include NMR [12], electrochemical [1], GC-FID [4,13], 
and LC-MS [8] detection of DP concentration. In order to improve the sensitivity of DP assays, some derivatization methods have been introduced. In most cases, these methods consist of hydrolysis of DP for the production of $\beta$-alanol (3-amino-1-propanol), a primary amine susceptible to the reaction of nitrobenzoxadiazole (NBD) and ninhydrin for the formulation of colored or fluorescent derivatives [12-19]. Thus, using fluorescence DP assays, it is possible to easily achieve LOD (Limit of Detection) as low as $10^{-8} \mathrm{~g} / \mathrm{mL}$ [12]. However, the above methods use HPLC separation or tedious DP extraction steps before the actual reaction with a derivatizing agent in order to reach an appropriate level of selectivity. The latter fact is associated with the ability of NBD and ninhydrine to react with all $\alpha$-amine-containing components of a studied sample and not only 3-amino-1-propanol [20,21]. Therefore, the requirement for a novel, simple, inexpensive, and sensitive protocol of DP determination in various complex formulations seems indisputable.

Citric acid (CA) is one of the most prominent carboxylic acids found in living organisms. CA is a crucial intermediate in the Krebs cycle occurring in the metabolism of all aerobic organisms [22]. Recently, CA has been investigated in terms of possible use as an inexpensive carbon source for bottom-up, hydrothermal synthesis of carbon dots [23-25] which resulted also in the development of a series of novel highly photoluminescent organic fluorophores, i.e., derivatives of ring-fused 2-pyridones [26-33]. The latter fluorophores were found to be a product of the condensation of CA and specific $\beta$-amines [29]. Taking into consideration the fact that DP moiety hydrolyzes to produce pantolactone (PAN) and 3-amino-1-propanol (3A1P) upon heating [34], it is reported that the latter is able to react with CA to produce a fluorescent derivative of 2-pyridone, simultaneously. Therefore, it was shown that by a careful choice of the derivatization conditions, the fluorescent signal of the reaction solution becomes proportional to the quantity of DP in the investigated samples. Thus, in this research, a novel spectrofluorimetric method for DP determination in various pharmaceutical and cosmetic formulations without a separate hydrolysis step of panthenol was introduced.

\section{Results and Discussion}

Considering that the concept of implementing CA as a derivatizing agent for DPs in the preparation of DP assay has not been described yet, it has been found necessary to elucidate the principles of the proposed procedure. The first paragraphs, consequently, discuss the chemical origin of the fluorescent signal that appears after the CA and DP thermal reaction. As a result, to determine the most optimal reaction conditions for the efficient synthesis of fluorescent molecules, three reaction parameters were differentiated, i.e., molar ratio $\mathrm{CA}: \mathrm{DP}$, temperature, and reaction time.

Therefore, several reactions differing in the molar ratio CA:DP were conducted, and the resulting reaction mixtures were dissolved in methanol and analyzed with LC-DAD-MS. On the LC-DAD chromatogram of the methanolic solutions of reaction mixtures, one main peak and several minor fractions absorbing around $350 \mathrm{~nm}$ were observed, indicating that the fluorophore was formed as a major component during the reaction (Figure 1A). The most prominent fraction (retention time $11.8 \mathrm{~min}$ ) was, therefore, investigated to reveal the nature of the proposed derivatization process. The above-mentioned fraction was found to have a molecular weight of $195 \mathrm{Da}\left(\mathrm{m} / z 196[\mathrm{M}+\mathrm{H}]^{+}\right)$ (Figure 1B). Moreover, comparing $\mathrm{m} / \mathrm{z} 196[\mathrm{M}+\mathrm{H}]^{+}$peak areas of chromatograms of samples prepared at various molar ratios of CA:DP, it was found that for the efficient synthesis of the fluorophore, the molar ratio of reagents 1:1 was the most suitable (Figure 1D). According to subsequent investigations, an increase in temperature and reaction time leads to a notable improvement in reaction efficiency; on the other hand, an increase in reaction time, especially when combined with high reaction temperature, results in a significant decrease in the area of the LC-DAD fluorophore peak (Figure 1C). The above fact is probably associated with the thermal decomposition of the product and/or polymerization as well as carbonization of the precursors leading to the formation of less PL emitting moieties, including carbon and graphene dots [35]. Ultimately, it was possible to synthesize and separate fluorophore in the proper amount and purity, thereby allowing for comprehensive characterization studies of the chemical structure (Figure S1). 

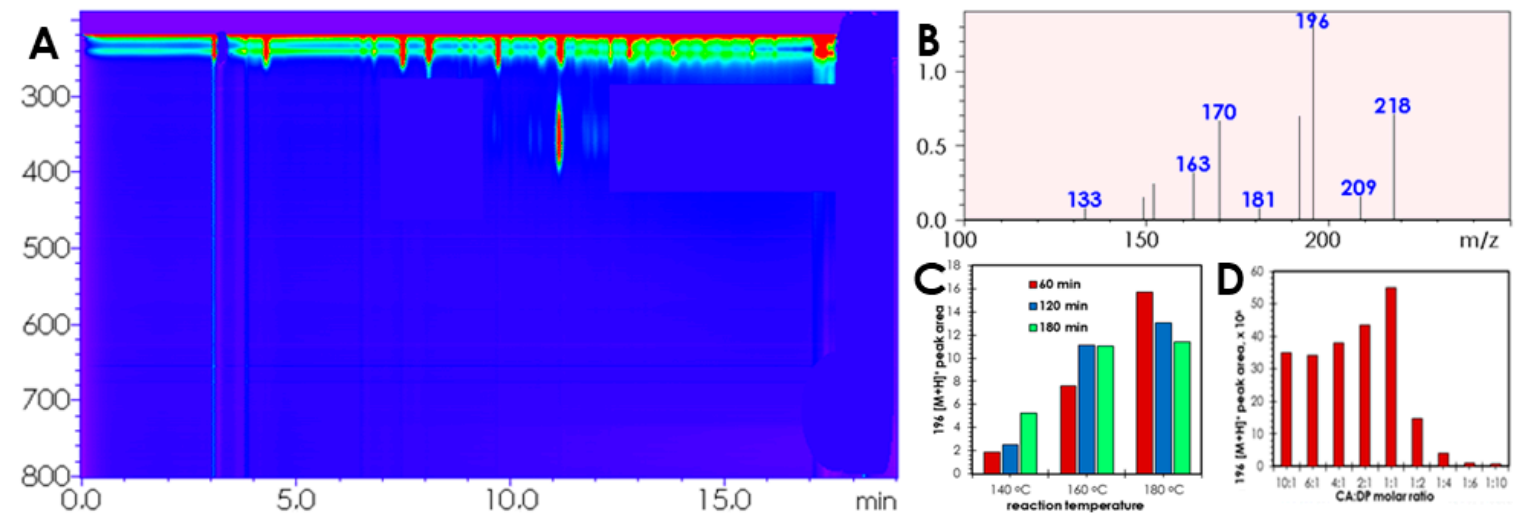

Figure 1. LC-DAD chromatogram of CA:DP reaction mixture $\left(1: 1 \mathrm{~mol} / \mathrm{mol}, 160{ }^{\circ} \mathrm{C}, 180 \mathrm{~min}\right)$ (A), mass spectra of fractions with retention times $\sim 11.8 \mathrm{~min}(\mathbf{B}, \mathbf{C})$ determination of the most optimal reaction conditions for the efficient synthesis of the fluorescent molecules $(\mathbf{D})$, determination of the ratio of CA:DP reagents for the most efficient fluorophore synthesis.

Simultaneously, CA was reacted with 3-amino-1-propanol and separately with pantolactone (thermal degradation products of panthenol) $[19,34]$ and resulting reaction mixtures were dissolved in methanol and analyzed with LC-DAD-MS. The above analyses were aimed at identifying the part of the DP molecule that is capable of reacting with CA to form a compound that absorbs around $350 \mathrm{~nm}$. This resulted in the conclusion that only in the reaction with 3-amino-1-propanol CA transforms into a molecule with absorption capacity at $\sim 350 \mathrm{~nm}$ (Figure S2). Furthermore, the mass analyses revealed that the same compound with a molecular weight of $195 \mathrm{Da}$ is formed following the reaction of CA with DP and CA with 3-amino-1-propanol (Figure S3). All the above indicates that during the derivatization of DP with CA, the DP molecule undergoes thermal hydrolysis, releasing 3-amino-1-propanol molecules capable of formation of the fluorescent compound in condensation with CA. Given the above observations and our previous experience in the synthesis of fluorescent compounds from citric acid, it was assumed that fluorophore contains ring-fused 2-pyridone derivative (6-oxo-3,4-dihydro-2H,6H-pyrido[2,1-b][1,3]oxazine-8-carboxylic acid) (ODPC), similar to those reported earlier in the literature [29].

In accordance, the proposed chemical structure of the blue-emitting moiety was undeniably confirmed in the form of in-depth NMR studies of pure compound isolated from the post-reaction mixture. In the ${ }^{1} \mathrm{H} N M R$ spectrum, two doublets ( $\delta 6.35$ and $\left.5.90 \mathrm{ppm}\right)$, two triplets ( $\delta 4.33$ and $\left.3.84 \mathrm{ppm}\right)$, and one quintet $(\delta 2.15 \mathrm{ppm})$ with integrals ratio 1:1:2:2:2 were found (Figure S4). Following the COrrelation SpectroscopY (COSY) ${ }^{1} \mathrm{H}-{ }^{1} \mathrm{H}$ experiment (Figure S5), four signals of correlated protons were shown, i.e., $6.35-5.90,3.84-4.33,3.84-2.15,4.33-2.15 \mathrm{ppm}$. The final two correlations indicate couplings of geminal methylene protons of the six-membered aliphatic ring, while signals at $\delta 6.35-5.90$ and 3.84-4.33 ppm were ascribed to long-distance correlations of methylene protons neighboring heteroatoms of the same ring and methine protons of the pyridine ring, respectively. For ${ }^{13} \mathrm{C}$ NMR, eight carbons lying in different chemical environments were observed (carbonyl- $\delta 166.5$, 161.7 ppm; heterocyclic— $\delta 8.2,108.1,142.8,156.3$ ppm; aliphatic-21.0, 65.7) (Figure S6). The signal originating from one of the aliphatic carbons of the fluorophore moiety was not observed in ${ }^{13} \mathrm{C}$ NMR spectra due to overlapping solvent signals. Fortunately, the above signal could be easily ascribed using the HSQC ${ }^{1} \mathrm{H}-{ }^{13} \mathrm{C}$ experiment, where the coupling of carbon with chemical shift $\delta 40.24 \mathrm{ppm}$ with methylene protons $\delta 3.85 \mathrm{ppm}$ was detected. The HSQC ${ }^{1} \mathrm{H}-{ }^{13} \mathrm{C}$ spectrum of the examined fluorophore further confirmed similarities in its chemical structure to previously reported 2-pyridone-based fluorophores, where signals originating from direct couplings of protons with appropriate carbons of the heterocyclic ring could be recognized (6.35-108.1, 5.91-88.13) [31]. The remaining two signals were ascribed to couplings between protons and carbons of methylene groups neighboring heteroatoms in a six-membered aliphatic ring (4.33-65.72, 2.14-20.98) (Figure S7). 
The ${ }^{1} \mathrm{H}_{-}{ }^{15} \mathrm{~N}$ HSQC and HMBC spectra (Figures S8 and S9) revealed that the fluorophore moiety is constituted by one nitrogen atom without a directly attached proton. Nevertheless, the nitrogen shows long-distance correlations characteristic of the pyridinic nitrogen of ring-fused 2-pyridone derivatives (6.35-168, 5.90-168, 3.84-168, 2.15-168 ppm). The multiple long-distance correlations between protons and carbons of the studied fluorophore (Table S2) were observed in the HMBC ${ }^{1} \mathrm{H}-{ }^{13} \mathrm{C}$ spectra (Figure 2A) and allowed for unambiguous confirmation of its chemical structure, which is constituted by 6-oxo-3,4-dihydro- $2 \mathrm{H}, 6 \mathrm{H}$-pyrido[2,1-b][1,3]oxazine-8-carboxylic acid (ODPC) (Figure 2B).

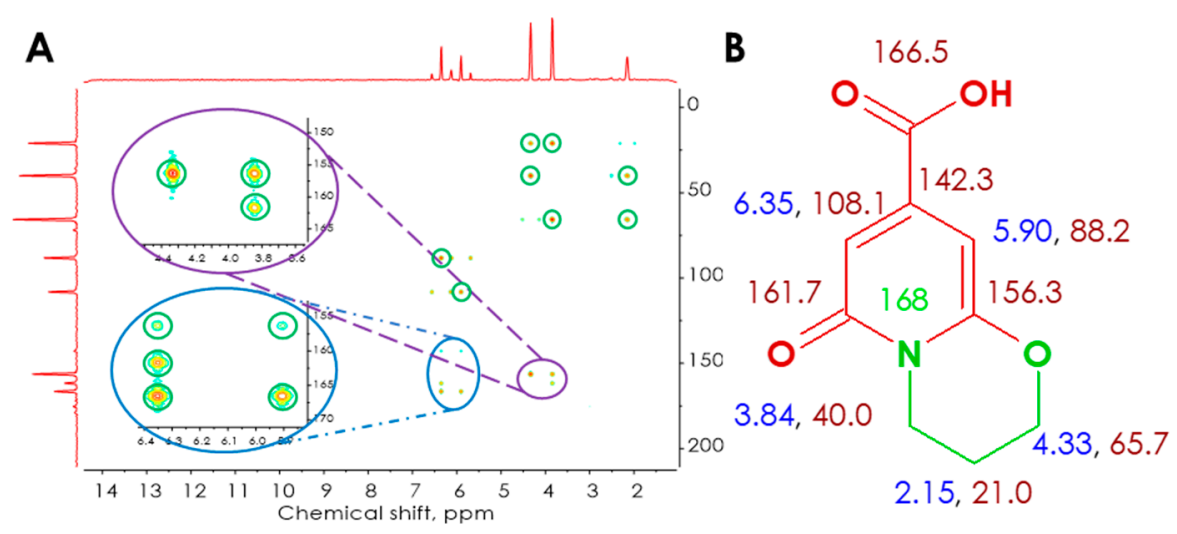

Figure 2. ${ }^{1} \mathrm{H}-{ }^{13} \mathrm{C}$ HMBC spectra of ODPC with appropriate extensions—significant correlation signals marked with green circles (A). Chemical structure of ODPC with relevant NMR assignments (B).

Thus, the probable mechanism of its formulation, in the course of thermal condensation of CA and DP, requires the formation of six-membered anhydride originating from dehydration of $C A$, thermal hydrolysis of amide linkage of DP resulting in the release of a 3-amino-1-propanol moiety, and inter- and intramolecular condensation of CA anhydride with 3-amino-1-propanol (Figure 3). The above investigations concerning the elucidation of the chemical structure of fluorescent dye may also be relevant to shed light on the molecular origin of the high PL quantum yield of many carbon dots prepared from citric acid and aminoalcohol derivatives reported so far [36-38].

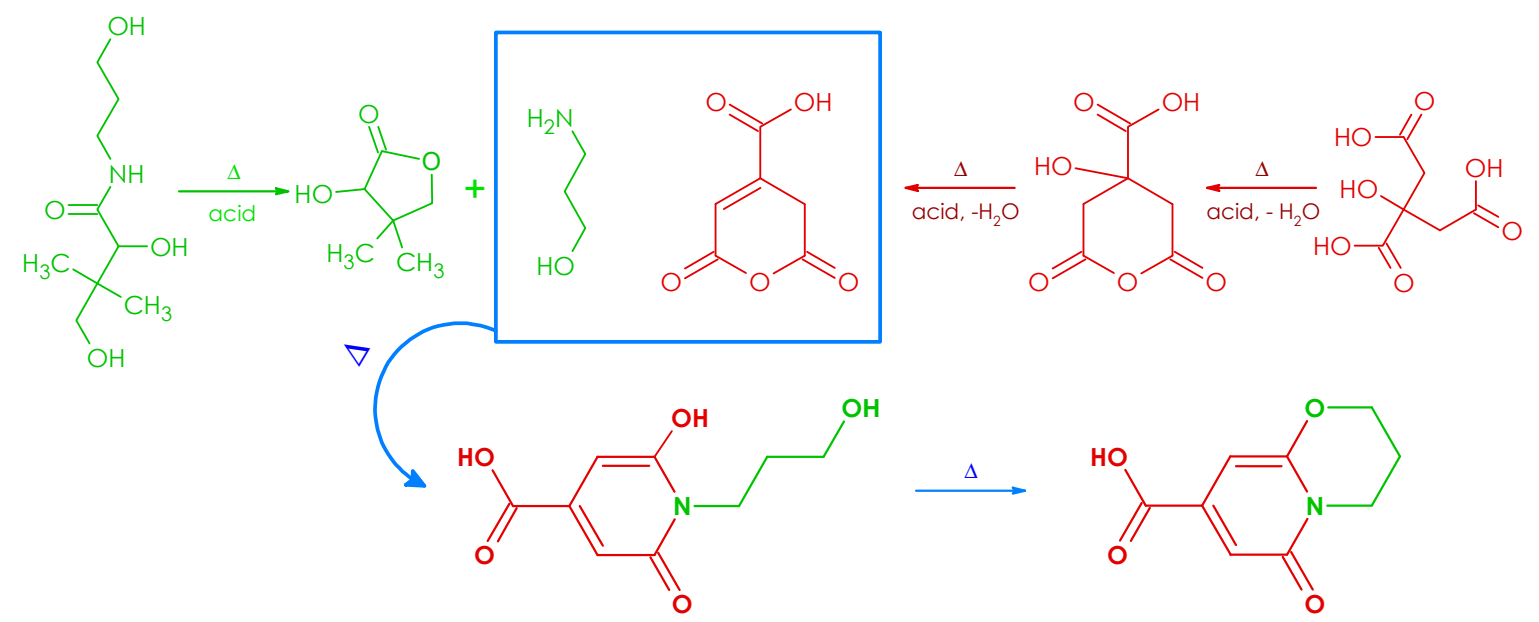

Figure 3. The possible mechanism of ODPC formulation in the course of thermal condensation of CA with DP.

Concerning the spectroscopic properties of ODPC, it was found that the aqueous solution of the above-mentioned fluorophore exhibits strong absorption bands of around 230 and $337 \mathrm{~nm}(343 \mathrm{~nm}$ for methanol ODPC solution) probably originating from the $\pi \rightarrow \pi^{*}$ transition of $\mathrm{sp}^{2}$ carbons of the 
heterocyclic 2-pyridone ring and to the $\mathrm{n} \rightarrow \pi^{*}$ transition of $\mathrm{C}=\mathrm{O}$ bonding (Figure $4 \mathrm{~A}$ ). ODPC exhibits excitation-independent PL spectra with a maximum emission wavelength at $419 \mathrm{~nm}(421 \mathrm{~nm}$ for the methanolic solution of ODPC) and a maximum of excitation wavelength at $342 \mathrm{~nm}$ ( $347 \mathrm{~nm}$ for the methanolic solution of ODPC) (Figure 4B-D). Broad and symmetrical PL emission spectra of ODPC display common tailing and Stokes shifts $(82 \mathrm{~nm}$ for an aqueous and $81 \mathrm{~nm}$ for a methanolic solution, respectively) reported for other organic fluorophores [39-41]. The PL QY of solutions of ODPC determined using the comparative method was 0.53 for methanolic and 0.64 for aqueous solutions. Consequently, ODPC resembles ring-fused 2-pyridone derivatives obtained in the reaction of CA and $\alpha, \beta$-diamines, $\beta$-aminoalcohols, and $\beta$-aminothiols in terms of optical properties [33].
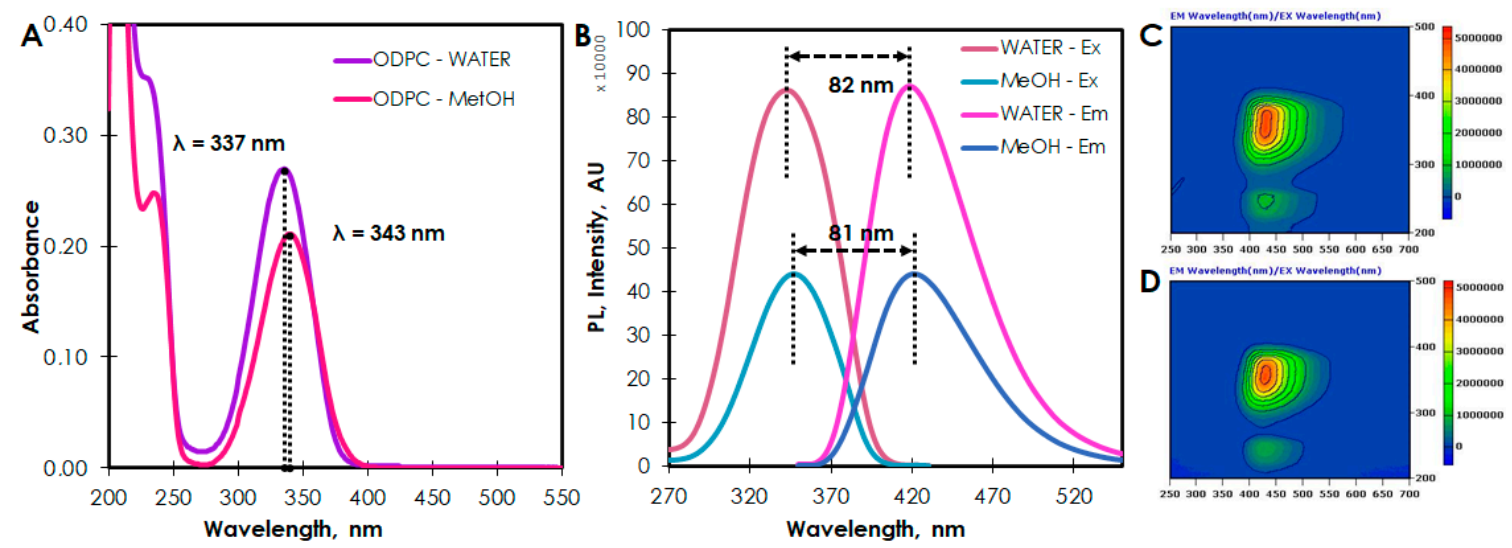

Figure 4. UV/VIS absorption spectrum of the aqueous and methanolic solution of ODPC (A), PL excitation and emission spectra of aqueous and methanolic solution of ODPC (B), and 3D excitation and emission spectra of aqueous (C) and methanolic (D) solution of ODPC.

Finally, in light of DP's ability to form highly fluorescent ring-fused 2-pyridone derivatives under thermal condensation with CA, the development of a CA-based DP assay using CA as a derivatizing agent has become feasible. Nevertheless, some crucial parameters of the derivatization process had to be precisely defined before proceeding with actual plotting of the DP assay calibration curve (i.e., CA:DP molar ratio, type of vessel used, time, and temperature). Although Figure 1D shows that the highest efficiency of ODPC formation under non-aqueous conditions can be achieved with a molar ratio of 1:1 CA:DP, the design of the functional DP assay requires to a large extent a derivatizing agent (despite the decrease in reaction efficiency). The latter fact is associated with the obligation that the developed protocol should be insensitive to possible CA-based additives in investigated samples, and the DP concentration vs. PL emission plot should be linear over a wide range of analyte concentrations. Therefore, throughout all experiments for the DP assay development, an excess of $\mathrm{CA}$ as a derivatizing agent was used. For the derivatization time and temperature, it was established that the process had to be conducted for $60 \mathrm{~min}$ at $160^{\circ} \mathrm{C}$ to ensure high sensitivity of the protocol within an acceptable period of time (Figure 5B). It was, furthermore, concluded that it is critical to carry out the derivatization of DPs in vessels with controlled release (Figure S10) to avoid rapid evaporation of aqueous solutions causing significant inhibition of ODPC formation and, in extreme cases, leading to a complete failure to apply the DP assay. Concluding all the above, the final conditions of derivatization that are relevant to the DP assay under consideration comprise the heating of the reagents for $60 \mathrm{~min}$ at $160^{\circ} \mathrm{C}$ in sealed vials with needles in caps and application of $150 \mathrm{mg} / \mathrm{mL}$ of CA $(1.5 \mathrm{~mL})$ and $1.5 \mathrm{~mL}$ of a sample. Thereafter, DP aqueous solutions were subject to derivatization with $\mathrm{CA}$ and resulting reaction mixtures were dissolved in methanol and their PL emission spectra were analyzed $\left(\lambda_{\mathrm{ex}}=347 \mathrm{~nm}, \lambda_{\mathrm{em}}=400-600 \mathrm{~nm}\right.$ ), enabling plotting of the DP calibration curve (Figure 5A). The latter indicates the high accuracy and reproducibility of the protocol $\left(R^{2}=0.999\right)$ within a broad DP concentration range, indicating good linearity. In order to evaluate the applicability of the developed DP assay, three different DP-containing pharmaceutical formulations supplied in the form of creams, 
lotions, and nasal spray applicators were analyzed. Hence, the resulting DP levels in the above products correlated well with the amounts of DP declared by the manufacturers and DP concentrations determined by the LC-ESI-MS method (Table 1) from the calibration curve (Figure S11).
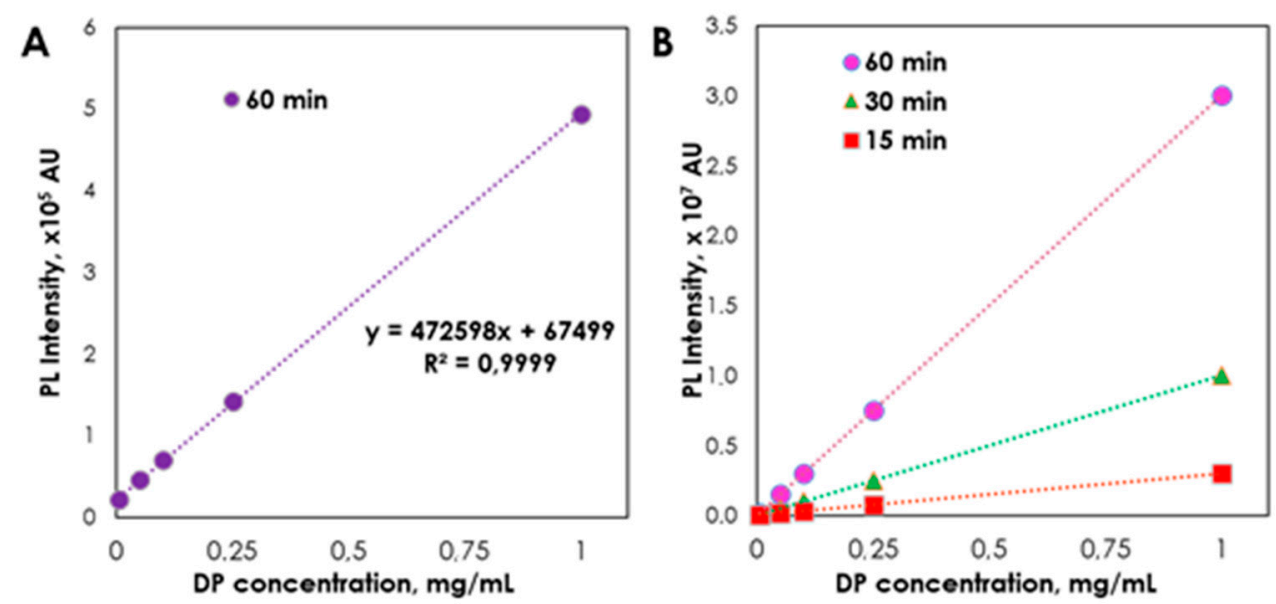

Figure 5. Linearity of the citric acid-panthenol derivatization process for solutions with different DP concentrations carried out for $60 \mathrm{~min}$ in sealed vials with needles in caps (A), at different reaction times (B).

Table 1. Validation of the method and results of the system applicability examination.

\begin{tabular}{|c|c|c|c|c|}
\hline \multirow[b]{2}{*}{ Parameters } & \multicolumn{4}{|c|}{ Method } \\
\hline & \multicolumn{2}{|c|}{ Fluorescence } & \multicolumn{2}{|c|}{ LC-MS } \\
\hline Regression equation & \multicolumn{2}{|c|}{$A=472598 x+67499$} & \multicolumn{2}{|c|}{$A=543834 x+63551$} \\
\hline Linear range $(\mathrm{mg} / \mathrm{mL})$ & \multicolumn{2}{|c|}{$0.005-1.000$} & \multicolumn{2}{|c|}{$0.005-1.000$} \\
\hline Limit of detection $(\mathrm{mg} / \mathrm{mL})$ & \multicolumn{2}{|c|}{0.001} & \multicolumn{2}{|c|}{0.0005} \\
\hline Limit of quantitation $(\mathrm{mg} / \mathrm{mL})$ & \multicolumn{2}{|c|}{0.005} & \multicolumn{2}{|c|}{0.0075} \\
\hline Correlation coefficients $(r)$ & \multicolumn{2}{|c|}{0.999} & \multicolumn{2}{|c|}{0.999} \\
\hline $\begin{array}{l}\text { Intraday precision and accuracy } \\
\qquad(\mathrm{mg} / \mathrm{mL})\end{array}$ & Accuracy, \% & Precision, RSD \% & Accuracy, \% & Precision, RSD \% \\
\hline 0.005 & 98.5 & 1.5 & 98.2 & 2.0 \\
\hline 0.05 & 99.1 & 1.8 & 98.1 & 1.7 \\
\hline 0.1 & 99.6 & 2.2 & 99.4 & 1.9 \\
\hline
\end{tabular}

Moreover, the precision of the proposed methods was determined in the range of concentrations presenting linearity, performing three measurements each on different days of the week. The target concentrations corresponded to the average values in each of the concentration ranges. Table 1 shows RSD concentrations and accuracy of $0.005,0.05$, and $0.1 \mathrm{mg} / \mathrm{mL}$ solutions determined according to the proposed procedure.

Three replications for the determination of panthenol were performed. Moreover, in order to evaluate the suitability of the proposed methods, a standard method of adding panthenol to the previously analyzed pharmaceutical products was used. The recovery of each product was calculated by comparing the concentration obtained from (spiked) mixtures with the concentration of pharmaceutical products. Table 2 presents the results of the analyses of commercial formulations with recovery (standard addition method) of panthenol. The comparison of the results obtained with the proposed method available in the literature $[42,43]$ shows that the accuracy of the results is acceptable. 
Table 2. Determination of panthenol in pharmaceutical formulations $(n=3)$.

\begin{tabular}{ccccccc}
\hline & \multicolumn{3}{c}{ Fluorescence Method } & \multicolumn{3}{c}{ LC-MS Method } \\
\cline { 2 - 7 } $\begin{array}{c}\text { Pharmaceutical } \\
\text { Formulations }\end{array}$ & $\begin{array}{c}\text { Found } \\
\text { (mg) }\end{array}$ & $\begin{array}{c}\text { Equivalent } \\
\text { Nominal } \\
\text { Content } \pm \text { S.D. } \\
\mathbf{( \% )}\end{array}$ & $\begin{array}{c}\text { Recovery } \\
\mathbf{( \% )}\end{array}$ & $\begin{array}{c}\text { Found } \\
\text { (mg) }\end{array}$ & $\begin{array}{c}\text { Equivalent } \\
\text { Nominal } \\
\text { Content } \pm \text { S.D. } \\
\mathbf{( \% )}\end{array}$ & $\begin{array}{c}\text { Recovery } \\
(\%)\end{array}$ \\
\hline nasal liquid & 49.8 & $99.52 \pm 1.10$ & $99.85 \pm 1.52$ & 49.9 & $99.62 \pm 1.11$ & $99.02 \pm 1.85$ \\
ointment & 49.5 & $98.92 \pm 1.52$ & $99.56 \pm 1.92$ & 49.5 & $99.12 \pm 2.52$ & $99.33 \pm 1.32$ \\
body lotion & 49.2 & $98.10 \pm 2.12$ & $99.46 \pm 1.82$ & 49.4 & $98.80 \pm 2.16$ & $99.36 \pm 1.12$ \\
\hline
\end{tabular}

These procedures are suitable for routine quality control of the compounds to be tested with minimal interference, due to the high-intensity fluorescent bands obtained and the absence of derivatizing reagent background. The proposed and reference methods have been used for the determination of panthenol-containing tested pharmaceutical products. The average values $( \pm$ S.D.) of the amounts determined varied slightly, indicating similar precision and accuracy. The results obtained indicate that the formation of fluorophore between citric acid and panthenol is favored and the reaction between the two chemical compounds can be used for spectrofluorometric analyses. Therefore, it became clear that CA could serve as an inexpensive DP derivatization agent which enables sensitive fluorescent determination of DP concentration in a variety of samples.

\section{Materials and Methods}

\subsection{Materials}

Citric acid (CA) (Sigma-Aldrich, Saint Louis, MO, USA), D-Panthenol (DP) (Fluorochem, Derbyshire, UK), 3-amino-1-propanol (3A1P) (Sigma-Aldrich), pantolactone (PAN) (Fluorochem), Coumarin 1 (Sigma-Aldrich), methanol MS grade (Avantor, Gliwice, Poland), acetone gradient grade (Avantor), ethanol (Avantor), dimethyl sulfoxide-d6 (Sigma-Aldrich). All chemicals and solvents were of analytical grade and used as received. Water used throughout the experiments with a resistivity of $18.0 \mathrm{~m} \Omega \mathrm{cm}^{-1}$ at $295 \mathrm{~K}$ was deionized through a Purix water purification system.

\subsection{Methods}

\subsubsection{Synthesis, Separation, and Structure Elucidation of the Fluorophore}

For the synthesis of the fluorophore to obtain the most favorable reaction conditions to elucidate its chemical structure, DP was reacted with different amounts of CA in glass vials at $160{ }^{\circ} \mathrm{C}$ for $3 \mathrm{~h}$ (Table S1A). Thereafter, each reaction mixture was dissolved in $7 \mathrm{~mL}$ of demineralized water using an ultrasonic bath. The prepared solutions of the post-reaction mixtures were evaluated by LC-ESI-MS analysis and the $\mathrm{m} / \mathrm{z} 196[\mathrm{M}+\mathrm{H}]^{+}$chromatogram peak areas of fractions with retention time $11.8 \mathrm{~min}$ were compared. Then, equimolar mixtures of CA $(242 \mathrm{mg})$ and DP $(258 \mathrm{mg})$ were heated at various temperatures $\left(140,160\right.$, and $\left.180^{\circ} \mathrm{C}\right)$ and for different periods of time $(1,2$, and $3 \mathrm{~h})$. Afterwards, each reaction mixture was dissolved in $7 \mathrm{~mL}$ of methanol and subjected to LC-ESI-MS analysis. Furthermore, to establish which part of DP chemical structure is responsible for formulation of fluorophore in reaction with CA, reactions of CA with DP thermal degradation products were conducted. Thus, CA (300 mg) was reacted with 3-amino-1-propanol (117 mg) (Table S1B) and pantolactone (203 mg) (Table S1C) in separate vials for $3 \mathrm{~h}$ at $160^{\circ} \mathrm{C}$ and then the reaction mixtures were dissolved in methanol and analyzed using LC-MS. For isolation of pure fluorophore, $1451 \mathrm{mg}$ of CA and $1549 \mathrm{mg}$ of DP (molar ratio 1:1) were weighed into a $7 \mathrm{~mL}$ vial and reacted for $1 \mathrm{~h}$ at $180^{\circ} \mathrm{C}$ in a heating block at $100 \mathrm{rpm}$. The sample after cooling was dissolved in $14 \mathrm{~mL}$ of methanol and then subjected to the next stage-separation by preparative liquid chromatography. The appropriate 
fluorescent fraction was isolated from the reaction mixture, freeze-dried, and its purity was confirmed using LC-DAD-ESI-MS analysis.

To characterize the elemental composition of the fluorophore, high-resolution mass spectrum was acquired using the MALDISynapt G2-S HDMS (Waters Corporation, Milford, MA, USA), coupled to a Waters TQD mass spectrometer (electrospray ionization mode ESI-tandem quadrupole). A constant flow of $0.3 \mathrm{~mL} / \mathrm{min}$ and two mobile phases were used: A-phase: $0.1 \%$ formic acid and B-phase: methanol. For chemical structure elucidation of the fluorophore ${ }^{1} \mathrm{H}$ and ${ }^{13} \mathrm{C}, \mathrm{COSY}{ }^{1} \mathrm{H}_{-}{ }^{1} \mathrm{H},{ }^{13} \mathrm{C}-{ }^{1} \mathrm{H}$ HSQC and HMBC, ${ }^{15} \mathrm{~N}^{-1} \mathrm{H}$ HSQC, and HMBC experiments were performed. NMR analyses were recorded on Avance III HD $400 \mathrm{MHz}$ (Bruker) in dimethyl sulfoxide-d6 as a solvent.

\subsubsection{Conditions of Chromatographic Separation}

For analytical low-resolution LC-ESI-MS/MS analyses, LCMS-8030 (Shimadzu, Kyoto, Japan) mass spectrometric system coupled to an LC-20ADXR pump utilizing the LC gradient was used. The LC analyses were carried out on a $100 \mathrm{~mm} \times 4.6 \mathrm{~mm} \times 5.0 \mu \mathrm{m}$ Kinetex C18 chromatographic column (Phenomenex, Torrance, CA, USA). Kinetex C18 chromatographic column was preceded by a guard column of the same material (Phenomenex, Torrance, CA, USA). The positive ion chromatograms and mass spectra were recorded by LabSolutions software version 5.91 (Shimadzu). The injection volume was $5 \mu \mathrm{L}$, and the flow rate was $0.5 \mathrm{~mL} / \mathrm{min}$. The column was thermostated at $40^{\circ} \mathrm{C}$. The separation of the analytes was performed with binary gradient elution. The mobile phases were: $\mathrm{A}-2 \%$ formic acid in the demineralized water, and B-pure methanol. The gradient profile was ( $\mathrm{t}[\mathrm{min}], \% \mathrm{~B}),(0,10)$, $(13,40),(15,90),(17,90)$.

A flash chromatography system was employed to isolate fluorescent fractions from reaction mixture solutions. Preparative HPLC system with LC-20AP pumps, UV-VIS SPD-20AV detector,

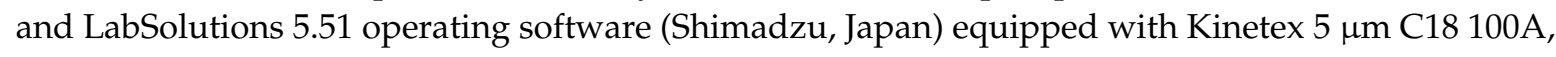
AXIA Packed HPLC Column $250 \times 21.2 \mathrm{~mm}$ preceded by a guard column of the same material was applied. Gradient elution was utilized consisting of phase A, which was $2 \%$ formic acid, and phase B, methanol. The mobile phase flow was $20 \mathrm{~mL} / \mathrm{min}$, and the injection volume was $20 \mathrm{~mL}$. The column was thermostated at $40^{\circ} \mathrm{C}$. The gradient profile was $(\mathrm{t}(\mathrm{min}), \% \mathrm{~B}),(0,10),(33,40),(38,90)$.

\subsubsection{Optical Properties Characterization}

UV-VIS absorption spectra of methanolic and aqueous solutions of the purified fluorophore as well as the ethanolic solution of coumarin 1 were analyzed. Samples were prepared by dissolving the previously freeze-dried compound in the above-mentioned solvents. The samples with a concentration of $0.002 \mathrm{mg} / \mathrm{mL}$ were subjected to recording spectra in range $200-600 \mathrm{~nm}$. For the analyses, a UV-2600i spectrophotometer from Shimadzu and quartz cuvettes with an optical path of $1 \mathrm{~cm}$ were used.

Fluorescence emission and excitation spectra of aqueous solutions of reaction mixtures, pure fluorophore, an ethanolic solution of coumarin 1 were acquired using RF-6000 spectrofluorometer (Shimadzu, Kyoto, Japan), both emission and excitation slits were set at $3 \mathrm{~nm}$, and an L-42 optical filter was used (340-420 nm). Fluorescence 3D spectra of the fluorophore were measured using the same equipment, excitation and emission slits were set at $3 \mathrm{~nm}$, excitation range $250-500 \mathrm{~nm}$, emission range 250-800 nm.

Fluorescence quantum yield (QY) determinations were conducted using a comparative method using coumarin 1 (fluorescence $\max 447 \mathrm{~nm}$, useful excitation range 320-420 (max 376) nm, absolute $\mathrm{QY}=0.73$ in ethanol [44])) as standard. All solutions were prepared in the absorption range $0.05-0.1$ $(355 \mathrm{~nm})$ to eliminate concentration quenching effects, and an L-42 optical filter was used (340-420 nm). The samples were excited at $355 \mathrm{~nm}$, and the fluorescence spectra were acquired between 380 and $700 \mathrm{~nm}$. The QY was calculated as follows:

$$
\Phi=\Phi_{s t} \frac{n^{2}\left(1-10^{-A_{s t}}\right) \int I_{e m} d v}{n_{s t}^{2}\left(1-10^{-A}\right) \int I_{e m}^{s t} d v}
$$


where:

$\Phi$ and $\Phi_{s t}$ - the quantum yield of a sample and the standard;

$A$ and $A_{s t}$-absorption of a sample and the standard at $408 \mathrm{~nm}$;

$\int I_{e m} d v$ and $\int I_{e m}^{s t} d v$-integral of fluorescence intensity of a sample and the standard; $n$ and $n_{s t}$-the refractive index of solvent used for a sample and the standard.

\subsection{Determination of DP Concentration}

\subsubsection{Preparation of Standard Solutions}

Stock standard solutions were prepared fresh before use by dissolving the weighed solid standard in deionized water (DP: molar mass $205.25 \mathrm{~g} / \mathrm{mol}$ and CA: molar mass $192.12 \mathrm{~g} / \mathrm{mol}$ ). They were further diluted with deionized water to obtain working solutions for derivatization. For DP (water solubility: $562.3 \mathrm{mg} / \mathrm{mL} ; 2{ }^{\circ} \mathrm{C}$ ), the concentrations of working solutions were as follows: $1 ; 0.25 ; 0.1 ; 0.05$; $0.005 \mathrm{mg} / \mathrm{mL}$. The concentration of CA working solution was $150 \mathrm{mg} / \mathrm{mL}$ (water solubility: $1630 \mathrm{mg} / \mathrm{mL}$; $\left.20{ }^{\circ} \mathrm{C}\right)$. The samples were stored in the dark, at low temperature $\left(5^{\circ} \mathrm{C}\right)$, for further processing. All solutions were filtered through a $0.20 \mu \mathrm{m}$ nylon syringe filter (PTFE, Sartorius, Germany) and then degassed in an ultrasonic bath for $15 \mathrm{~min}$.

\subsubsection{Derivatization of DP}

For derivatization of DP, $1.5 \mathrm{~mL}$ of CA working solution was mixed with $1.5 \mathrm{~mL}$ of DP working solution in $7 \mathrm{~mL}$ glass vial reactors (in triplicate) equipped with a magnetic stirring bar. The vials were placed on a heating block, and the derivatization reaction occurred at $160{ }^{\circ} \mathrm{C}$ for $1 \mathrm{~h}$. Finally, the reaction mixtures were dissolved in $7 \mathrm{~mL}$ of methanol, the PL emission spectra of the solutions were acquired, and the calibration curve was calculated. The wavelength for the PL excitation was $347 \mathrm{~nm}$; PL emission range was set to 380-700 $\mathrm{nm}$. All samples were degassed in an ultrasonic bath for 5 min before experiments and $15 \mathrm{~min}$ after the reaction to increase the dissolution process in methanol.

\subsubsection{Pharmaceutical Sample Preparation}

The preparation of the pharmaceutical samples was considered crucial, with many interfering substances in the matrix. The first step was to separate the dissolved pharmaceutical in deionized water from insoluble additives. Therefore, optimization based on a simple, one-step sample preparation technique provides an especially useful tool for conducting reactions with pharmaceutical solutions. Consequently, $1 \mathrm{~g}$ of the formulation (50 mg DP declared) was transferred into a $500 \mathrm{~mL}$ volumetric flask and diluted with deionized water. The dissolution of the pharmaceutical was supported by an ultrasonic bath for $15 \mathrm{~min}$. Then, the suspension was filtered using a syringe filter (PTFE, $0.20 \mu \mathrm{m}$ ); the resulting solution was diluted 10-fold (approx. $0.2 \mathrm{mg} / \mathrm{mL}$ ) with deionized water and derivatized under the conditions specified above.

\section{Conclusions}

The chemical structure of the new fluorophore (ODPC) was elucidated using detailed NMR experiments, allowing us to suggest a possible mechanism for its formation involving the formation of six-membered anhydride originated from dehydration of CA, thermal hydrolysis of amide linkage of DP resulting in the release of a 3-amino-1-propanol moiety, and inter- and intramolecular condensation of CA anhydride with 3-amino-1-propanol. Furthermore, optical properties of ODPC resemble those ascribed to similar ring-fused 2-pyridone fluorophores reported earlier. A profound understanding of the chemical and optical properties of ODPC allowed for evolving a novel DP assay which involves the utilization of CA as a derivatization agent. Critical parameters of the derivatization procedure (reaction time, temperature, molar ratio, solvent, and fitting of reaction vessels) were established. The DP determination method demonstrates high accuracy and reproducibility 
$\left(\mathrm{R}^{2}=0.999\right.$, accuracy $98.5-99.6 \%$, precision (RDS\%) 1.5-2.2) within a wide range of DP concentrations: $0.005-1 \mathrm{mg} / \mathrm{mL}$. Furthermore, the established protocol proved to be of high accuracy in the determination of DP levels in pharmaceutical formulations (validated using LC-MS DP determination method). Thus, all the above argue in favor of the novelty of the presented work, while its complexity and diversity can become a starting point for various, more detailed studies and give rise to the development of novel fluorescence determination methods for a variety of important chemical species.

Supplementary Materials: The following are available online at http://www.mdpi.com/1422-0067/21/21/8386/s1. Table S1. Molar ratios for reactions of citric acid in glass vial reactors at $160{ }^{\circ} \mathrm{C}$ for 3 hours with DP (A), 3A1P (B), PAN (C). Figure S1. LC-DAD chromatogram of pure fluorophore separated from the reaction mixture (retention time: $11.8 \mathrm{~min}$ ) (A). LC chromatogram of the pure fluorophore calculated from a maximum plot of 190-800 nm (retention time: $11.8 \mathrm{~min}$ ) (B). Figure S2. LC-DAD chromatogram of CA:3A1P reaction mixture $(1: 1 \mathrm{~mol} / \mathrm{mol}$. $\left.160^{\circ} \mathrm{C} .180 \mathrm{~min}\right)(\mathrm{A})$. and LC-DAD chromatogram of CA:PAN reaction mixture $\left(1: 1 \mathrm{~mol} / \mathrm{mol} .160{ }^{\circ} \mathrm{C} .180 \mathrm{~min}\right)(\mathrm{B})$. Figure S3. The mass spectrum of the fraction with a retention time of 11.8 minutes formed in a reaction with a molar ratio from CA:31AP 1:1. Figure S4. ${ }^{1} \mathrm{H}$ NMR of the fluorescent fraction. Figure S5. ${ }^{1} \mathrm{H}-{ }^{1} \mathrm{H}$ COSY NMR of the fluorescent fraction. Figure S6. ${ }^{13} \mathrm{C}$ NMR of the fluorescent fraction. Figure S7. ${ }^{1} \mathrm{H}-{ }^{13} \mathrm{C}$ HSQC NMR of the fluorescent fraction. Figure S8. ${ }^{1} \mathrm{H}_{-}{ }^{15} \mathrm{~N}$ HSQC of the fluorescent fraction. Figure S9. ${ }^{1} \mathrm{H}_{-}{ }^{15} \mathrm{~N}$ HMBC of the fluorescent fraction. Table S2. Couplings between the atoms in ${ }^{1} \mathrm{H}^{13} \mathrm{C}$ HMBC NMR of the fluorescent fraction. Figure S10. The type of vessel used in the process of panthenol derivatization. Figure S11. LC-MS calibration curve for the determination of panthenol in pharmaceutical formulations (calculated from the area under the curves).

Author Contributions: Conceptualization, methodology, investigation, visualization, writing一original draft preparation, writing - review and editing, W.K.; methodology, investigation, visualization, review and editing, T.Ś.; investigation, F.K. All authors have read and agreed to the published version of the manuscript.

Funding: This research was financed by the Polish National Science Centre for years 2018-2021-SONATINA No. UMO-2018/28/C/ST5/00461.

Conflicts of Interest: The authors declare no conflict of interest.

\section{References}

1. Wang, L.H.; Tseng, S.W. Direct determination of D-panthenol and salt of pantothenic acid in cosmetic and pharmaceutical preparations by differential pulse voltammetry. Anal. Chim. Acta 2001, 432, 39-48. [CrossRef]

2. Prival, M.J.; Simmon, V.F.; Mortelmans, K.E. Bacterial mutagenicity testing of 49 food ingredients gives very few positive results. Mutat. Res. Toxicol. 1991, 260, 321-329. [CrossRef]

3. Ishidate, M.; Sofuni, T.; Yoshikawa, K.; Hayashi, M.; Nohmi, T.; Sawada, M.; Matsuoka, A. Primary mutagenicity screening of food additives currently used in Japan. Food Chem. Toxicol. 1984, 22, $623-636$. [CrossRef]

4. König, W.A.; Sturm, U. Determination of optical purity by enantioselective capillary gas chromatography: panthenol and related compounds. J. Chromatogr. A 1985, 328, 357-361. [CrossRef]

5. Zholobak, N.M.; Shcherbakov, A.B.; Bogorad-Kobelska, A.S.; Ivanova, O.S.; Baranchikov, A.Y.; Spivak, N.Y.; Ivanov, V.K. Panthenol-stabilized cerium dioxide nanoparticles for cosmeceutic formulations against ROS-induced and UV-induced damage. J. Photochem. Photobiol. B Biol. 2014, 130, 102-108. [CrossRef]

6. Kobayashi, D.; Kusama, M.; Onda, M.; Nakahata, N. The effect of pantothenic acid deficiency on keratinocyte proliferation and the synthesis of keratinocyte growth factor and collagen in fibroblasts. J. Pharmacol. Sci. 2011, 115, 230-234. [CrossRef] [PubMed]

7. Semieka, M.A.; Ali, M.M.; Khafar, S.A.; Al-lethie, A. lethie A.; Elmeligy, E. Comparative Study of the Therapeutic Effect of Panthenol Gel and Mebo Ointment on Metacarpal Wound Healing in Donkeys. J. Equine Vet. Sci. 2019, 74, 21-27. [CrossRef]

8. Khater, S.; West, C. Development and validation of a supercritical fluid chromatography method for the direct determination of enantiomeric purity of provitamin B5 in cosmetic formulations with mass spectrometric detection. J. Pharm. Biomed. Anal. 2015, 102, 321-325. [CrossRef]

9. Vidović, S.; Stojanović, B.; Veljković, J.; Pražić-Arsić, L.; Roglić, G.; Manojlović, D. Simultaneous determination of some water-soluble vitamins and preservatives in multivitamin syrup by validated stability-indicating high-performance liquid chromatography method. J. Chromatogr. A 2008, 1202, 155-162. [CrossRef] 
10. Bui-nguyen, M.H. Direct determination of D-panthenol in pharmaceutical preparations by ion-pair chromatography. J. Chromatogr. 1984, 303, 291-295. [CrossRef]

11. Kulikov, A.U.; Zinchenko, A.A. Development and validation of reversed phase high performance liquid chromatography method for determination of dexpanthenol in pharmaceutical formulations. J. Pharm. Biomed. Anal. 2007, 43, 983-988. [CrossRef] [PubMed]

12. Shehata, M.A.M.; Tawakkol, S.M.; Abdel Fattah, L.E. Colorimetric and fluorimetric methods for determination of panthenol in cosmetic and pharmaceutical formulation. J. Pharm. Biomed. Anal. 2002, 27, 729-735. [CrossRef]

13. Tarli, P.; Benocci, S.; Neri, P. Gas-chromatographic determination of pantothenates and panthenol in pharmaceutical preparations by pantoyl lactone. Anal. Biochem. 1971, 42, 8-13. [CrossRef]

14. Eid, M.I.; Wahba, M.E.K. Analytical and Stability Studies on Medical Cosmetics. Am. J. Anal. Chem. 2012, 03, 277-281. [CrossRef]

15. Shehata, M.A.; Tawakkol, S.M. Spectrophotometric and Fluorimetric Methods for Determination of Additives in Cosmetics and Pharmaceutical Formulations. Saudi Pharm. J. 2014, 12, $29-34$.

16. Prosser, A.R.; Sheppard, A.J. Gas-liquid chromatographic determination of pantothenates and panthenol. J. Pharm. Sci. 1969, 58, 718-721. [CrossRef] [PubMed]

17. Panier, R.G.; Close, J.A. Quantitative fluorometric determination of panthenol in multivitamin preparations. J. Pharm. Sci. 1964, 53, 108-110. [CrossRef]

18. Uehara, N.; Ookubo, K.; Shimizu, T. Colorimetric assay of glutathione based on the spontaneous disassembly of aggregated gold nanocomposites conjugated with water-soluble polymer. Langmuir 2010, 26, 6818-6825. [CrossRef]

19. Shimizu, S.; Tani, Y.; Ogata, K. Diversity of the Degradation of Panthenol by Microorganisms. Agric. Biol. Chem. 1974, 38, 1989. [CrossRef]

20. Samejima, K.; Dairman, W.; Stone, J.; Udenfriend, S. Condensation of ninhydrin with aldehydes and primary amines to yield highly fluorescent ternary products. II. Application to the Detection and Assay of Peptides, Amino Acids, Amines, and Amino Sugars. Anal. Biochem. 1971, 42, 237-247. [CrossRef]

21. Zacharis, C.K.; Tzanavaras, P.D.; Mouroutis, P.N.; Rigas, P.G. NBD-Cl as a post-column reagent for primary and secondary amines after separation by ion-exchange chromatography. Anal. Lett. 2011, 44, 1821-1834. [CrossRef]

22. Tran, R.T.; Yang, J.; Ameer, G.A. Citrate-Based Biomaterials and Their Applications in Regenerative Engineering. Annu. Rev. Mater. Res. 2015, 45, 1-34. [CrossRef] [PubMed]

23. Hola, K.; Zhang, Y.; Wang, Y.; Giannelis, E.P.; Zboril, R.; Rogach, A.L. Carbon dots - Emerging light emitters for bioimaging, cancer therapy and optoelectronics. Nano Today 2014, 9, 590-603. [CrossRef]

24. Reckmeier, C.J.; Schneider, J.; Susha, A.S.; Rogach, A.L. Luminescent colloidal carbon dots: optical properties and effects of doping [Invited]. Opt. Express 2016, 24, A312. [CrossRef]

25. Fu, M.; Ehrat, F.; Wang, Y.; Milowska, K.Z.; Reckmeier, C.; Rogach, A.L.; Stolarczyk, J.K.; Urban, A.S.; Feldmann, J. Carbon Dots: A Unique Fluorescent Cocktail of Polycyclic Aromatic Hydrocarbons. Nano Lett. 2015, 15, 6030-6035. [CrossRef]

26. Schneider, J.; Reckmeier, C.J.; Xiong, Y.; Von, M.; Susha, A.S.; Kasak, P.; Rogach, A.L. Molecular Fluorescence in Citric Acid Based Carbon Dots. J. Phys. Chem. Lett. 2017, 121, 2014-2022. [CrossRef]

27. Ehrat, F.; Bhattacharyya, S.; Schneider, J.; Löf, A.; Wyrwich, R.; Rogach, A.L.; Stolarczyk, J.K.; Urban, A.S.; Feldmann, J. Tracking the Source of Carbon Dot Photoluminescence: Aromatic Domains versus Molecular Fluorophores. Nano Lett. 2017, 17, 7710. [CrossRef]

28. Kasprzyk, W.; Bednarz, S.; Walas, K.; Bashmakova, N.V. Nanoscale from citric acid and urea-A molecular insight †. Nanoscale 2018, 13889-13894. [CrossRef]

29. Kasprzyk, W.; Bednarz, S.; Żmudzki, P.; Galica, M.; Bogdał, D. Novel efficient fluorophores synthesized from citric acid. RSC Adv. 2015, 5, 34795-34799. [CrossRef]

30. Kasprzyk, W.; Krzywda, P.; Bednarz, S.; Bogdał, D. Fluorescent citric acid-modified silicone materials. RSC Adv. 2015, 5. [CrossRef]

31. Kasprzyk, W.; Bednarz, S.; Bogdał, D. Luminescence phenomena of biodegradable photoluminescent poly(diol citrates). Chem. Commun. 2013, 49, 6445-6447. [CrossRef]

32. Kim, J.P.; Xie, Z.; Creer, M.; Liu, Z.; Yang, J. Citrate-based fluorescent materials for low-cost chloride sensing in the diagnosis of cystic fibrosis. Chem. Sci. 2016, 8. [CrossRef] 
33. Liu, M.; Lu, X.; Hu, L.; Liu, C.; Li, Y.; Zhang, W.; Ding, C.; Gu, J.; Cao, F. Hydrothermal synthesis of a highly photoluminescent molecule from citric acid and cysteamine for the e ffi cient detection of $\mathrm{Au}^{3+}$ in aqueous solution. Opt. Mater. (Amst.) 2019, 96, 109359. [CrossRef]

34. Rubin, S.H. The Comparative Stability of Pantothenic Acid and Panthenol. J. Am. Pharm. Assoc. (Sci. Ed.) 1948, 37, 502-504. [CrossRef] [PubMed]

35. Zhu, S.; Zhao, X.; Song, Y.; Lu, S.; Yang, B. Beyond bottom-up carbon nanodots: Citric-acid derived organic molecules. Nano Today 2015. [CrossRef]

36. Dong, X.; Su, Y.; Geng, H.; Li, Z.; Yang, C.; Li, X.; Zhang, Y. Fast one-step synthesis of N-doped carbon dots by pyrolyzing ethanolamine. J. Mater. Chem. C 2014, 2, 7477. [CrossRef]

37. Du, F.; Min, Y.; Zeng, F.; Yu, C.; Wu, S. A targeted and FRET-based ratiometric fluorescent nanoprobe for imaging mitochondrial hydrogen peroxide in living cells. Small 2014, 10, 964-972. [CrossRef] [PubMed]

38. Bourlinos, A.B.; Stassinopoulos, A.; Anglos, D.; Zboril, R.; Karakassides, M.; Giannelis, E.P. Surface functionalized carbogenic quantum dots. Small 2008, 4, 455-458. [CrossRef] [PubMed]

39. Lakowicz, J.R. Principles of Fluorescence Spectroscopy, 3rd ed.; Springer: Berlin/Heilderlberg, Germany, 2006; ISBN 978-0-387-31278-1.

40. Kamińska, I.; Ortyl, J.; Popielarz, R. Mechanism of interaction of coumarin-based fluorescent molecular probes with polymerizing medium during free radical polymerization of a monomer. Polym. Test. 2016, 55, 310-317. [CrossRef]

41. Ortyl, J.; Fiedor, P.; Chachaj-Brekiesz, A.; Pilch, M.; Hola, E.; Galek, M. The applicability of 2-amino4,6-diphenyl-pyridine-3-carbonitrile sensors for monitoring different types of photopolymerization processes and acceleration of cationic and free-radical photopolymerization under near UV light. Sensors 2019, 19, 1668. [CrossRef]

42. Lomenova, A.; Hroboňová, K.; Šolónyová, T. HPLC separation of panthenol enantiomers on different types of chiral stationary phases. Acta Chim. Slovaca 2018, 11, 114-119. [CrossRef]

43. Hroboňová, K.; Lomenova, A. Determination of panthenol enantiomers in cosmetic preparations using an achiral-chiral-coupled column HPLC system. Chirality 2020, 32, 191-199. [CrossRef]

44. Jones, G.; Jackson, W.R.; Choi, C.Y.; Bergmark, W.R. Solvent effects on emission yield and lifetime for coumarin laser dyes. Requirements for a rotatory decay mechanism. J. Phys. Chem. 1985, 89, 294-300. [CrossRef]

Publisher's Note: MDPI stays neutral with regard to jurisdictional claims in published maps and institutional affiliations.

(C) 2020 by the authors. Licensee MDPI, Basel, Switzerland. This article is an open access article distributed under the terms and conditions of the Creative Commons Attribution (CC BY) license (http://creativecommons.org/licenses/by/4.0/). 